\title{
DISTRIBUIÇÃO DA UMIDADE NUM PERFIL DE SOLO IRRIGADO POR GOTEJAMENTO SUPERFICIAL E SUBSUPERFICIAL
}

\author{
Humidity distribution in a soil profile irrigated by surface and buried drip systems
}

\author{
Elves de Almeida Souza ${ }^{1}$, Eugênio Ferreira Coelho ${ }^{2}$, Vital Pedro da Silva Paz ${ }^{3}$
}

\begin{abstract}
RESUMO
Conduziu-se o presente trabalho com o objetivo de avaliar a distribuição de água no perfil de um Latossolo cultivado com mamoeiro do grupo Formosa, irrigado por dois gotejadores por planta instalados a $0,30 \mathrm{~m}$ da mesma. Usou-se gotejamento superficial com emissores de vazão de 3,75 L.h $h^{-1}$ e subsuperficial com emissores de vazão foi $2 \mathrm{~L}^{-h^{-1}}$ a $0,25 \mathrm{~m}$ de profundidade. Os valores de umidades foram obtidos por meio de sondas de TDR instaladas e distribuídas em perfis de solo. As leituras foram realizadas em intervalos de dez minutos, durante dois ciclos de irrigação, utilizando um sistema de aquisição de dados composto por uma TDR, um datalogger e quatro multiplexadores. Os dados foram analisados a partir de isolinhas de distribuição de umidade e os resultados mostraram que o sistema de gotejamento subsuperficial apresentou uma menor variação da umidade concentrada na direção do sistema radicular do mamoeiro e o armazenamento de água no sistema subsuperficial foi $17 \%$ superior ao superficial.
\end{abstract}

Termos para indexação: TDR, volume molhado, monitoramento da água no solo.

\begin{abstract}
This work aimed at evaluating water distribution in a Latossol profile cultivated with papaya of Formosa group, irrigated by two drippers per plant installed at $0.30 \mathrm{~m}$ from the plant. Surface drip irrigation with emitters of $3.75 \mathrm{Lh}^{-1} \mathrm{flow}$ rate and subsurface drip with emitters of $2 \mathrm{Lh}^{-1}$ at $0.25 \mathrm{~m}$ depth were used. The humidity values were obtained by means of TDR probes installed and distributed in soil profiles. The readings were performed in a ten-minute interval during two irrigation cycles, using a data acquisition system composed by a TDR, one datalloger and four multiplexers. The data were analyzed from isolines of humidity distribution and results showed that the subsurface drip system had a smaller variation of humidity concentrated in the direction of papaya root system. The water storage for the subsurface system was $17 \%$ larger than the one for surface system.
\end{abstract}

Index terms: TDR, wetted volume, soil water monitoring.

(Recebido em 19 de abril de 2005 e aprovado em 22 de agosto de 2006)

\section{INTRODUÇÃO}

Segundo Phene et al. (1987) e Phene \& Howell (1984), o sistema de irrigação por gotejamento subsuperficial apresenta algumas vantagens em relação ao superficial, tais como: aumento substancial na eficiência de irrigação, aplicação de água e maior durabilidade, aumentando assim a disponibilidade de nutrientes e a redução da área de evaporação de água a partir da superfície do solo. Com isso, proporciona um bulbo molhado de forma esférica, com umedecimento de um volume de solo até $46 \%$ maior que o verificado no gotejamento superficial, aumentando assim a eficiência na absorção de água (PHENE et al., 1987).

A distribuição de água no bulbo molhado depende do volume, da vazão do gotejador, da posição (na superfície do solo ou enterrado), da disposição dos gotejadores (fonte pontual ou fonte em linha), do número de gotejadores, das propriedades físicas do solo, como a textura, densidade do solo e o seu grau de compactação modificam o bulbo úmido, de sua distribuição espacial, da atividade do sistema radicular das plantas e do manejo da irrigação (COELHO \& OR, 1996). Em solos argilosos, o bulbo tende a ser mais extenso lateralmente e pouco profundo, devido às forças capilares mais acentuadas nesses solos. Nos solos arenosos ocorre o contrário, o movimento de água é maior na direção vertical, por sua vez os solos de textura franca apresentam uma forma intermediária (GOMES, 1994).

Nogueira et al. (2000) afirmam que, para efeito de cálculo dos limites do bulbo úmido, a expansão do bulbo é determinada pela isolinha de umidade mais próxima do emissor que permanece inalterada, após sucessivas irrigações.

A determinação da umidade no solo pode ser efetuada por diversos métodos, como a gravimetria (GARDNER, 1986) considerado método-padrão e por métodos que estimam a umidade a partir de outras

\footnotetext{
1Engenheiro Agrícola, Mestre em Ciências Agrárias - Secretaria de Fazenda - Prefeitura Municipal de Cruz das Almas - 44380-000 - Cruz das Almas, BA elvis_eas@hotmail.com

2Engenheiro Agrônomo, Ph. D. em Engenharia de Irrigação - Laboratório de Irrigação e Fertirrigação - EMBRAPA Mandioca e Fruticultura Tropical Rua Embrapa, s/n - 44380-000 - Cruz das Almas, BA - ecoelho@cnpmf.embrapa.br

${ }^{3}$ Engenheiro Agrícola, Doutor em Agronomia - Nucleo de Engenharia de Agua e Solo/NEAS - Universidade Federal do Reconcavo da Bahia/ UFRB Campus UFRB - 44380-000 - Cruz das Almas, BA - vpspaz@ufrb.br
} 
propriedades do solo, tais como termalização de nêutrons (GARDNER, 1986), resistência elétrica (SPAANS \& BAKER, 1992), dissipação de calor (PHENE et al., 1973) e a reflectometria no domínio do tempo (TDR). A reflectometria no domínio do tempo apresenta algumas vantagens, principalmente pela precisão, possibilidade de multiplicação de leituras, repetição sem destruição da amostra de solo, com segurança (OR \& WRAITH, 1997; TOPP et al., 1980).

O uso da TDR como técnica para a determinação da umidade é feita a partir da relação dos teores de umidade do solo com os valores da constante dielétrica aparente, por meio de curvas de calibração obtidas a partir de dados de campo ou de laboratório (CONCIANI et al., 1997).

Realizou-se este estudo com o objetivo de avaliar a distribuição da umidade no volume molhado, sob irrigação por gotejamento superficial e subsuperficial, com uso da técnica da reflectometria no domínio do tempo (TDR).

\section{MATERIAL E MÉTODOS}

O trabalho foi desenvolvido na área experimental da Embrapa Mandioca e Fruticultura, localizada no município de Cruz das Almas-Ba. O clima da região é classificado como úmido sub-úmido. O solo da área é classificado como Latossolo Amarelo com textura argilosa, com $444 \mathrm{~g} . \mathrm{kg}^{-1}$ de areia total, $131 \mathrm{~g}$. kg-1 de silte, $425 \mathrm{~g} \cdot \mathrm{kg}^{-1}$ de argila, densidade de $1,36 \mathrm{~kg} \mathrm{dm}^{-3}$ (SOUZA \& SOUZA, 2001); umidade do solo correspondente a capacidade de campo $0,29 \mathrm{~m}^{3} \cdot \mathrm{m}^{-3}$ equivalente a tensão $10 \mathrm{kPa}$ e a umidade correspondente ao ponto de murcha permanente $0,17 \mathrm{~m}^{3} \cdot \mathrm{m}^{-3}$ equivalente a tensão $1.500 \mathrm{kPa}$, apresentando a curva de retenção ilustrada na Figura 1. O experimento foi conduzido em um pomar de mamoeiros (Carica papaya L.), cultivar Tainung $\mathrm{n}^{\circ} 1$, do grupo Formosa, instalado em dezembro de 2002 , no espaçamento $3,5 \times 1,5 \mathrm{~m}$, irrigado numa freqüência diária por gotejamento superficial e subsuperficial com dois gotejadores por planta, instalados a $0,30 \mathrm{~m}$ da mesma. No sistema superficial a vazão dos gotejadores foi de $3,75 \mathrm{~L} \cdot \mathrm{h}^{-1}$ e no subsuperficial, a vazão foi de $2 \mathrm{~L} \cdot \mathrm{h}^{-1}$ com o emissor a $0,25 \mathrm{~m}$ de profundidade.

Foram selecionadas duas plantas por sistema de irrigação aos nove dias do plantio, sendo que, para cada planta foi aberta, antes do plantio, uma trincheira longitudinal à fileira de plantas.

Sondas de TDR foram construídas e conectadas a multiplexadores de leituras do tipo SMDX, que, por sua vez, foram ligados ao reflectômetro TDR 100 (Campbell Scientific). A sonda foi construída com três hastes de 0,15 $\mathrm{m}$, espaçadas $0,022 \mathrm{~m}$, com inclusão de um resistor de 15 ohms em série com a haste central e o terminal positivo do

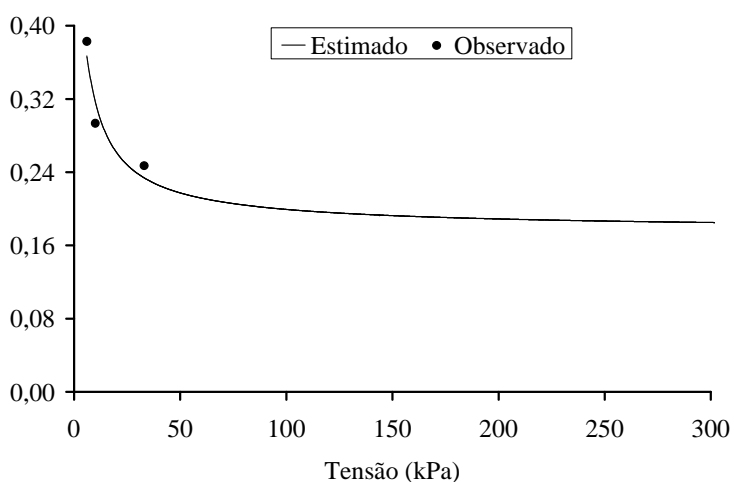

FIGURA 1 - Curva de retenção de água no solo da área experimental.

cabo RG 58. A relação entre a umidade (q) e a constante dielétrica aparente $(\mathrm{Ka})$ apresentou uma equação polinomial do $3^{\circ}$ da seguinte forma:

$\theta=4 \times 10^{-5} \mathrm{Ka}^{3}-0,0015 \mathrm{Ka}^{2}+0,0302 \mathrm{Ka}-0,0411 \quad$ com $\mathrm{R}^{2}=0,9845$.

As sondas de TDR foram instaladas nas trincheiras às profundidades de 0,$20 ; 0,40 ; 0,60 \mathrm{e} 0,80 \mathrm{~m}$ e às distâncias horizontais da planta de $0 ; 0,15 ; 0,30 ; 0,45 ; 0,60$ e $0,75 \mathrm{~m}$. A umidade do solo foi monitorada de uma hora antes da irrigação até 24 horas após a irrigação, sendo as leituras realizadas a cada 10 minutos pelo sistema de aquisição de dados, o que permitiu leituras simultâneas de 19 posições no perfil. Considerou-se o perfil do solo onde as sondas de TDR foram instaladas, com um volume correspondente a uma seção de $0,75 \mathrm{~m}$ x $0,80 \mathrm{~m}$ e $0,15 \mathrm{~m}$ de espessura, equivalente ao comprimento das hastes das sondas de TDR para a aferição das dimensões do bulbo molhado, para a determinação do armazenamento de água e para a determinação da água disponível no solo nos dois sistemas. $\mathrm{O}$ volume total de água armazenado no solo considerado num determinado tempo foi calculado pela somatória das umidades em cada posição, nos nós da malha, que representou o volume unitário de $0,15 \mathrm{~m}$ x $0,20 \mathrm{~m}$ x $0,15 \mathrm{~m}$ monitoradas nesse intervalo de tempo (Figura 2).

Para a determinação da água disponível no perfil convertendo-se a umidade em cada nó da malha em água disponível do solo, conforme as equações:

$$
\mathrm{AD}^{\prime}=\left(\frac{\theta-\theta \mathrm{pmp}}{\theta \mathrm{cc}-\theta \mathrm{pmp}}\right) * 100
$$

em que:

$A D^{\prime}$ - porcentagem de água disponível no perfil do solo $(\%)$; 
$\theta$ - umidade atual do solo obtida pela TDR $\left(\mathrm{m}^{3} \cdot \mathrm{m}^{-3}\right)$; өqpmp - ponto de murcha permanente $\left(\mathrm{m}^{3} \cdot \mathrm{m}^{-3}\right)$; $\theta c c$ - capacidade de campo $\left(\mathrm{m}^{3} \cdot \mathrm{m}^{-3}\right)$.

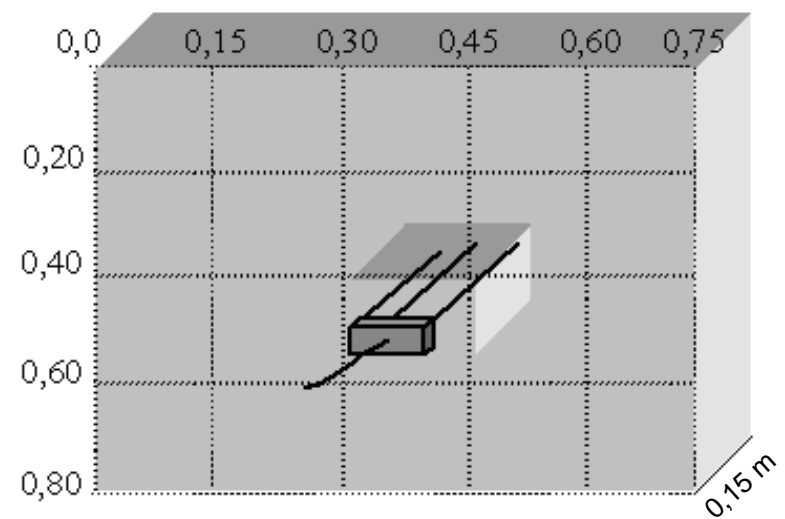

FIGURA 2 - Volume de solo monitorado em diversas posições com sondas de TDR de hastes de $0,15 \mathrm{~m}$.

O armazenamento total de água no perfil do solo, correspondente a uma seção de $0,75 \mathrm{~m}$ x $0,80 \mathrm{~m}$ e $0,15 \mathrm{~m}$ de espessura, foi obtido pela integração dos volumes unitários de solo da malha, contado no período entre duas irrigações pela seguinte equação:

$$
\mathrm{V}_{\mathrm{t}}=\sum_{\mathrm{i}} \sum_{\mathrm{j}} \Delta \theta_{\mathrm{ij}} \mathrm{v}_{\mathrm{ij}}
$$

em que:

$\mathrm{V}_{\mathrm{t}}=$ volume total de água no perfil $\left(\mathrm{m}^{3}\right) ;$

$\Delta \theta_{\mathrm{ij}}=$ Diferença entre as umidade do solo entre duas irrigações $\left(\mathrm{m}^{3} \cdot \mathrm{m}^{-3}\right)$;

$\mathrm{i}=$ distância horizontal, que variou de 0 a $0,75 \mathrm{~m}$;

$\mathrm{j}=$ profundidade, que variou de 0 a $0,80 \mathrm{~m}$;

$\mathrm{v}_{\mathrm{ij}}=$ volume unitário do solo água representante da posição ij $\left(\mathrm{m}^{3}\right)$.

Foram avaliados planos bidimensionais com isolinhas de umidade e de água disponível no solo correspondentes aos perfis para o gotejamento superficial e subsuperficial. O monitoramento da umidade foi feito após um evento de irrigação de 2,17 h para o gotejamento superficial e de 4,6 h para o gotejamento enterrado.

\section{RESULTADOS E DISCUSSÃO}

\section{Gotejamento superficial}

Na Figura 3, ilustra-se a distribuição de umidade no perfil do solo na direção longitudinal à fileira de plantas, uma hora antes do início da irrigação, para o gotejamento superficial. Os maiores valores de umidade encontram-se abaixo do gotejador até a profundidade de $0,42 \mathrm{~m}$ e entre as distâncias da planta de $0,27 \mathrm{~m} \mathrm{e} \mathrm{0,37} \mathrm{m}$.

$\mathrm{O}$ volume molhado apresentou um formato próximo ao de uma semi-esfera, com dimensões limitadas pela isolinha de $0,22 \mathrm{~m}^{3} \cdot \mathrm{m}^{-3}$, tendo um comprimento na horizontal até $0,55 \mathrm{~m}$, entre as distâncias horizontais de 0,10 e $0,65 \mathrm{~m}$ da planta e profundidade de $0,70 \mathrm{~m}$, tendo ocorrido maior expansão do mesmo em profundidade do que em distância horizontal.

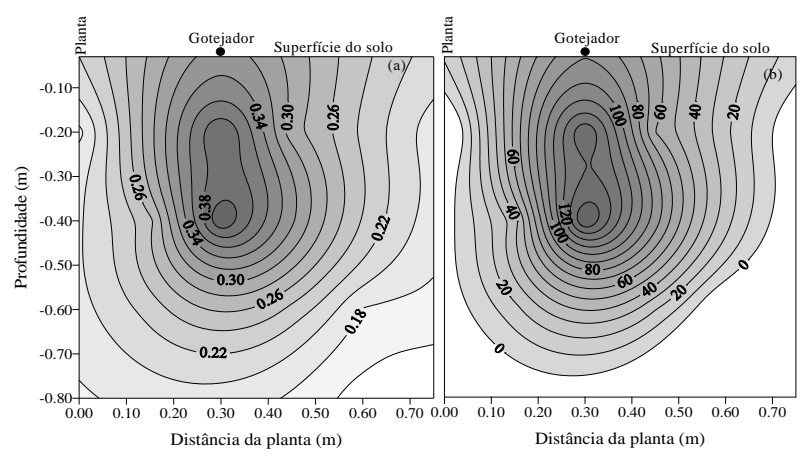

FIGURA 3 - Distribuição da umidade $\left(\mathrm{m}^{3} \cdot \mathrm{m}^{-3}\right)$ (a) e da água disponível (b) no perfil do solo, com o gotejador a 0,30 m da planta, uma hora antes da irrigação.

Pela Figura 3b, mostra-se que a disponibilidade de água dentro do volume molhado variou de $30 \%$ na borda até $130 \%$ embaixo do gotejador, entre as profundidades de 0,20 e $0,40 \mathrm{~m}$. Se considerar o limite crítico de água disponível (redução permissível de umidade a partir do limite superior de disponibilidade ou capacidade de campo) de 50\%, a região do volume molhado onde a absorção de água ocorreria em melhores condições estaria entre $0,12 \mathrm{~m}$ e 0,55 $\mathrm{m}$ de distância da planta, isto é, as distâncias horizontais do emissor entre $0,18 \mathrm{~m}$ e $0,25 \mathrm{~m}$ e profundidades do solo até $0,60 \mathrm{~m}$.

A distribuição de umidade no perfil uma hora após a irrigação é ilustrada na Figura 4. Os maiores valores de umidade do solo foram encontrados abaixo do gotejador entre as profundidades de 0,30 e 0,44 $\mathrm{m}$ do gotejador e as distâncias da planta de 0,20 e 0,40 m.

As dimensões do volume molhado pouco se alteraram uma hora após a irrigação, ocorrendo apenas, uma expansão de $22 \%$ na distância horizontal e $11 \%$ em profundidade das isolinhas de maior umidade dentro do 
bulbo úmido em todas as direções a partir da superfície do solo (Figura 4). Este comportamento foi seguido pela porcentagem de água disponível, com uma expansão em todas as direções, ultrapassando as suas dimensões no evento anterior, com uma expansão desta região limítrofe a $50 \%$ da água disponível, para a distância horizontal entre o gotejador $0,10 \mathrm{~m}$ a $0,57 \mathrm{~m}$ e a profundidade de até $0,64 \mathrm{~m}$ (Figura 4b). Uma região abaixo do gotejador, a profundidade entre 0,30 e $0,50 \mathrm{~m}$ apresentou umidade acima da capacidade de campo (água disponível superior a 100\%).

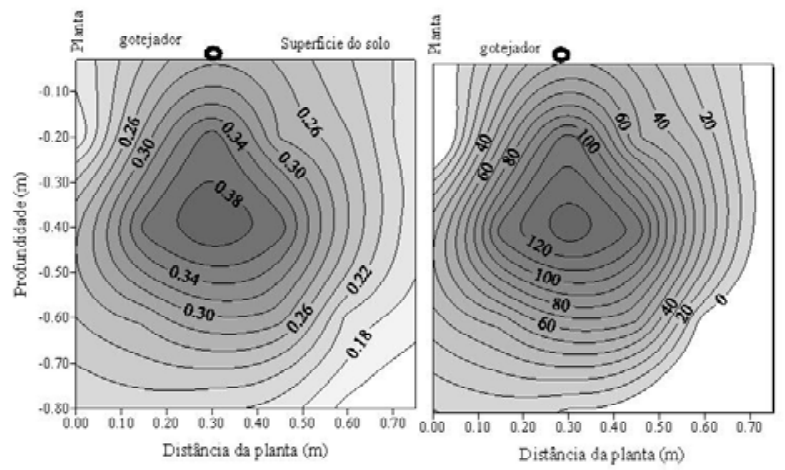

FIGURA 4 - Distribuição da umidade $\left(\mathrm{m}^{3} \cdot \mathrm{m}^{-3}\right)$ (a) e da água disponível (b) no perfil do solo, com o gotejador a 0,30 m da planta, uma hora após a irrigação.

Na Figura 5, demonstra-se que a distribuição de umidade no perfil do solo 24 horas após a irrigação pouco se alterou, devido à alta frequiência de aplicação de água do sistema de gotejamento, mantendo a umidade do solo próxima a capacidade de campo. Houve uma redução na área limitada por isolinhas de água disponível superior a $100 \%$, o que pode ser atribuído principalmente a redistribuição da água no solo, a possível extração de água pela planta e a evaporação da água do solo, que se encontrava descoberto no momento das leituras (Figura 5).

\section{Gotejamento Subsuperficial}

Pela Figura 6, ilustra-se a distribuição de umidade no perfil do solo uma hora antes da irrigação, por gotejamento subsuperficial, no perfil longitudinal à fileira de plantas. A isolinha correspondente a umidade de 0,22 $\mathrm{m}^{3} \cdot \mathrm{m}^{-3}$ delimita o bulbo úmido na profundidade a partir de $0,10 \mathrm{~m}$ do gotejador, até $0,54 \mathrm{~m}$ de distância horizontal da planta. Em profundidade, o gotejamento subsuperficial proporcionou uma expansão mais acentuada desta isolinha, ultrapassando as dimensões do perfil monitorado pelo TDR. Os limites da disponibilidade de água a 50\% ficaram

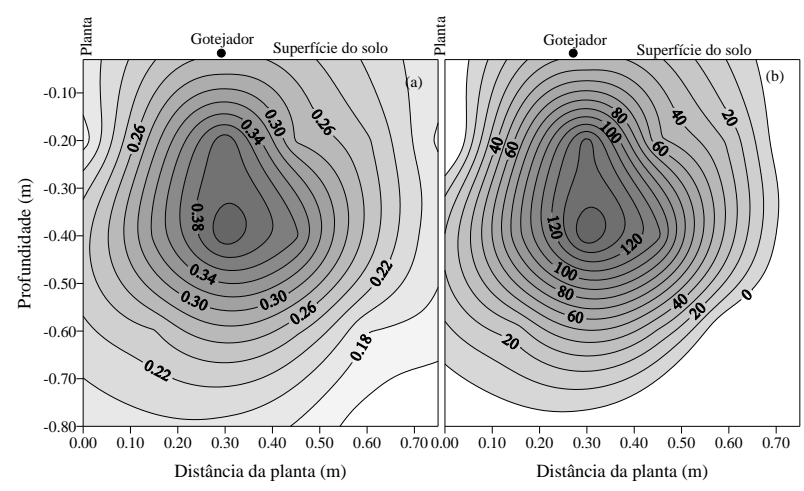

FIGURA 5 - Distribuição da umidade $\left(\mathrm{m}^{3} \cdot \mathrm{m}^{-3}\right)$ (a) e da água disponível (b) no perfil do solo, com o gotejador a 0,30 m da planta, 24 horas após a irrigação.

restritos a profundidade de $0,10 \mathrm{~m}$ acima do gotejador e a distância horizontal de $0,12 \mathrm{~m}$ do gotejador. Abaixo do gotejador a região do volume molhado delimitada pela isolinha de $50 \%$ de água disponível se estende a profundidades maiores que $0,80 \mathrm{~m}$ (Figura 6b).

A distribuição de umidade uma hora após a irrigação está representada na Figura 7. Os maiores valores de umidade estão localizados na região entre 0,37 e 0,65 m de profundidade em relação ao gotejador e a distância da planta entre 0,23 e $0,30 \mathrm{~m}$, não ultrapassando a umidade de $0,35 \mathrm{~m}^{3} \cdot \mathrm{m}^{-3}$. O sistema superficial ultrapassou estes limites com umidades superiores, o que era esperado, dado que o volume molhado no gotejamento superficial é inferior ao volume molhado do gotejamento subsuperficial; como foram aplicados os mesmos volumes de água nos dois sistemas, houve maior volume de água para o mesmo volume de poros no sistema superficial.

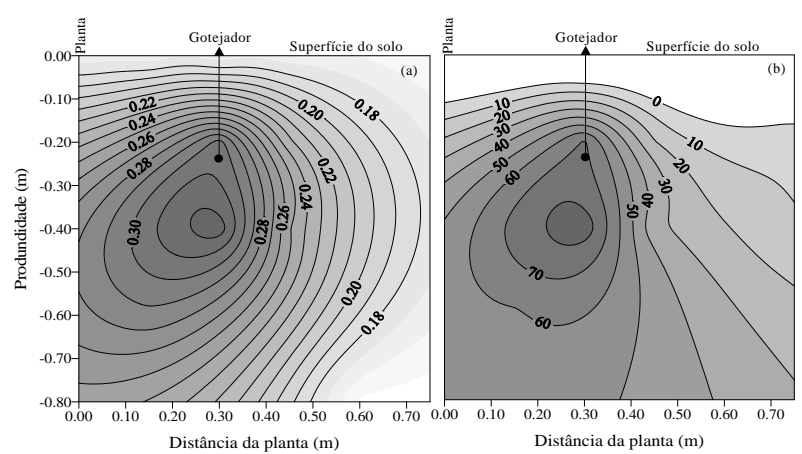

FIGURA 6 - Distribuição de umidade $\left(\mathrm{m}^{3} \cdot \mathrm{m}^{-3}\right)$ (a) e da água disponível (b) no perfil do solo, uma hora antes da irrigação com o gotejador a $0,30 \mathrm{~m}$ da planta e enterrado a $0,25 \mathrm{~m}$. 


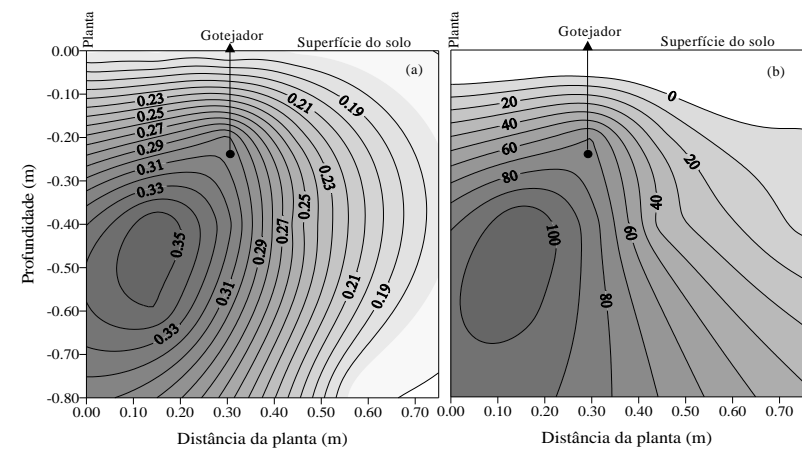

FIGURA 7 - Distribuição de umidade $\left(\mathrm{m}^{3} \cdot \mathrm{m}^{-3}\right)$ (a) e da água disponível (b) no perfil do solo, uma hora após a irrigação, com o gotejador a $0,30 \mathrm{~m}$ da planta enterrado a $0,25 \mathrm{~m}$

Segundo Phene et al. (1987), o sistema de gotejamento subsuperficial apresenta um volume de solo até $46 \%$ maior que o verificado no gotejamento superficial, proporcionando uma distribuição da umidade no perfil mais uniforme. A irrigação proporcionou um deslocamento descendente das isolinhas de maior umidade dentro do bulbo úmido (Figura 7), que podem ultrapassar os limites de extração de água do sistema radicular, indicando a possibilidade de perdas de água por percolação profunda, promovendo perdas de água e nutrientes, pela lixiviação, diferindo de Phene \& Howell (1984). As dimensões do volume molhado pouco se alteraram uma hora após a irrigação, sendo que a isolinha de $0,22 \mathrm{~m}^{3} \cdot \mathrm{m}^{-3}$ não se alterou, delimitando o bulbo úmido. Houve um deslocamento da isolinha equivalente a $50 \%$ de disponibilidade de água após a irrigação, na vertical para baixo, com uma expansão desta região a partir da profundidade de $0,40 \mathrm{~m}$ até a $0,35 \mathrm{~m}$ de distância horizontal do gotejador, ultrapassando o limite do perfil em estudo, de 0,80 $\mathrm{m}$ de profundidade (Figura 7b).

A distribuição da umidade no perfil 24 horas após a irrigação por gotejamento subsuperficial é ilustrada na Figura 8. O sistema apresentou uma maior estabilidade temporal da umidade dentro do perfil. A distribuição da umidade pouco se alterou em relação a uma hora antes da irrigação, apresentado dimensões semelhantes em umidade no perfil para as isolinhas estudadas.

Pela Figura 8b são mostradas as isolinhas de água disponível com uma dimensão semelhante ao ocorrido uma hora antes da irrigação, principalmente a isolinha de 50\% de disponibilidade de água. Se considerar os valores de umidade próximo da capacidade de campo e acima de 50\% da disponibilidade de água, como a zona de maior atividade do sistema radicular das culturas, pode-se considerar que no sistema de gotejo subsuperficial há chances de um maior aprofundamento do sistema radicular.

No gotejamento subsuperficial a redução dos valores de umidade foi desuniforme dentro do perfil, mais restrito e próximo ao tronco da planta, indicando a possibilidade da sobreposição entre os bulbos dos dois gotejadores, com um deslocamento descendente das isolinhas de maior umidade; já para o gotejamento superficial ocorreu de forma uniforme do interior do bulbo entre as bordas, obedecendo ao processo de redistribuição, uma vez que a água tende a se deslocar das regiões mais úmidas para aquela de menor umidade.

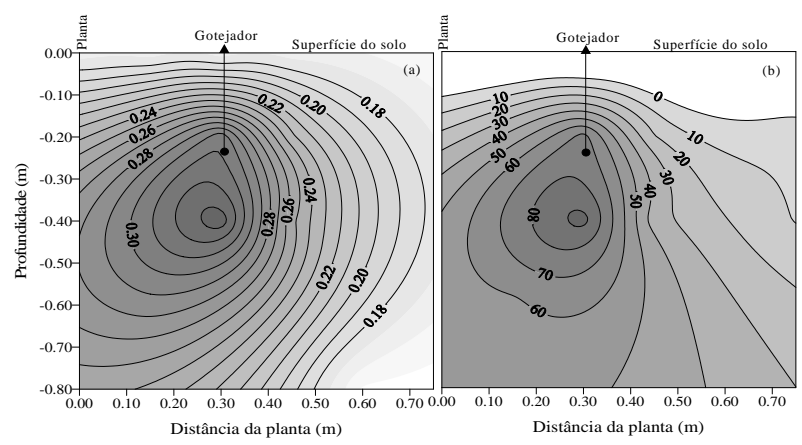

FIGURA 8 - Distribuição de umidade $\left(\mathrm{m}^{3} \cdot \mathrm{m}^{-3}\right)$ (a) e da água disponível (b) no perfil do solo, 24 horas após a irrigação com o gotejador a $0,30 \mathrm{~m}$ da planta e enterrado a $0,25 \mathrm{~m}$.

Na Figura 9, mostra-se o volume de água armazenado no perfil em instantes de 2 a 24 horas após a irrigação. Na comparação dos dois sistemas verifica-se que o sistema subsuperficial ocorreu uma variação de 5,8\% do volume de água armazenado do solo e no superficial esta variação foi de $19,3 \%$ e a diferença de volume de água armazenada do sistema superficial para o enterrado foi em média de $17,7 \%$. As diferenças de armazenamento de água entre os sistemas podem ser atribuídas principalmente à ocorrência de maior evaporação do sistema superficial comparado com o subsuperficial, uma vez que as condições das plantas e da atmosfera possivelmente ocasionaram transpiração semelhante nos dois sistemas. Estes resultados são concordantes com Nogueira et al. (2000) e Phene \& Howell (1984). 


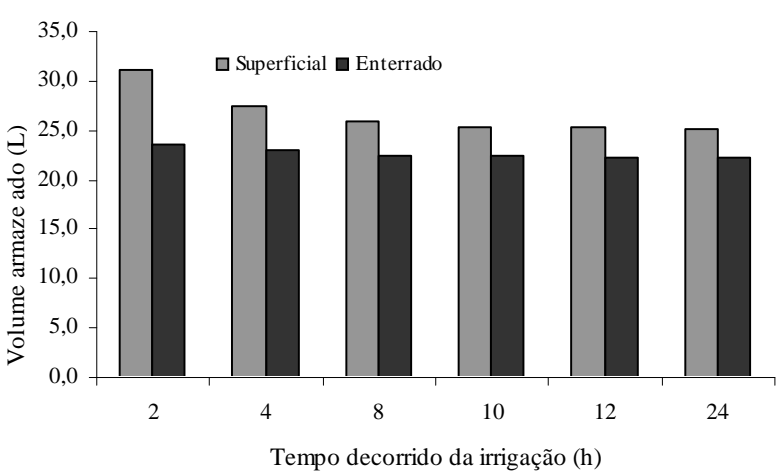

FIGURA 9 - Volume de água armazenado num volume de solo medindo $0,75 \mathrm{~m}$ de distância horizontal x $0,80 \mathrm{~m}$ de profundidade $\mathrm{x} 0,15 \mathrm{~m}$ de espessura, no período entre duas irrigações.

\section{CONCLUSÕES}

O gotejamento subsuperficial apresentou menor expansão lateral e maior expansão vertical do bulbo úmido;

$\mathrm{O}$ volume de água armazenado no sistema de gotejamento superficial diferiu em média do sistema enterrado em $17,7 \%$ entre duas irrigações;

O sistema de gotejamento subsuperficial apresentou menor variação da umidade no perfil do solo em relação ao gotejamento superficial;

A distribuição da umidade no sistema superficial ocorreu de forma uniforme e integral dentro do perfil em relação ao sistema subsuperficial.

\section{REFERÊNCIAS BIBLIOGRÁFICAS}

COELHO, E. F.; OR, D. A parametric model for twodimensional water uptake by corn roots under drip irrigation. Soil Science Society of America Journal, Madison, v. 60, n. 4, p. 1039-1049, 1996.

CONCIANI, W.; CARNEIRO, B. J.; SOARES, M. M.; HERMANN, P. S. P.; CRESTANA, S. Emprego de TDR com sondas multihastes segmentadas para medida de umidade de um perfil de solo. In: SIMPÓSIO NACIONAL DE INSTRUMENTAÇÃO AGROPECUÁRIA, 1997, São Carlos. Anais... São Carlos: Embrapa-CNPDIA, 1997. v. 1, p. 169-173.

GARDNER, W. H. Water content. In: Methods of soil analysis. Madison: A. Klute, 1986. p. 493-544.
GOMES, H. P. Engenhraira de irrigação: hidráulica dos sistemas pressurizados aspersão e gotejamento. João Pessoa: UFPB, 1994. 344 p.

NOGUEIRA, C. C. P. Características e dimensões do volume de um solo molhado sob gotejamento superficial e subsuperficial. Revista Brasileira de Engenharia Agrícola e Ambiental, Campina Grande, v. 4, n. 3, p. 315320,2000 .

OR, D.; WRAITH, J. M. Agricultural and enviromental soil physics. Utah State University, Logan, p. 218, 1997.

PHENE, C. J.; DAVIS, K. R.; HUTMACHER, R. B.; McCORMICK, R. L. Advantages of subsurface irrigation for processing tomatoes. In: INTERNATIONAL SYPOSIUM ON INTEGRATED MANAGEMENT PRACTICES FOR TOMATO AND PEPPER PRODUCTION IN THE TROPICS, 1987, Shanhua, Taiwan. Proceedings... Shanhua: [s.n.], 1987. p. 325338.

PHENE, C. J.; HOFFMAN, G. J.; AUSTIN, R. S. Controlling automated irrigation with soil matric potencial sensor. Transactions of the ASAE, Saint Joseph, v. 16, p. 773-776, 1973.

PHENE, C. J.; HOWELL, T. A. Soil sensor control of high frequency irrigation. Trans ASAE, Saint Joseph, v. 27, n. 2, p. 392-396, 1984.

SOUZA, L. da S.; SOUZA, L. D. Caracterização físicohídrica de solos da área do Centro Nacional de Pesquisa de Mandioca e Fruticultura Tropical, Cruz das Almas, Bahia. Cruz das Almas: Embrapa-CNPMF, 2001. p. 56. (Boletim de Pesquisa, 20).

SPAANS, E. J. A.; BAKER, J. Calibration of watermark soil moisture sensors for soil matric potential and temperature. Plant and Soil, The Hague, v. 143, p. 213217, 1992

TOPP, G. C.; DAVIS, J. L.; ANNAN, A. Electromagnetic determination of soil water content: measurement in coaxial transmission lines. Water Resources Research, Washington, v. 16, p. 576-583, 1980. 